\title{
GENTRIFICAÇÃO: ASPECTOS CONCEITUAIS E PRÁTICOS DE SUA VERIFICAÇÃO NO BRASIL
}

GENTRIFICATION: CONCEPTUAL AND PRACTICAL ASPECTS OF ITS VERIFICATION

IN BRAZIL

\author{
Tarcyla Fidalgo Ribeiro ${ }^{1}$
}

\section{Resumo}

Muito tem se falado, especialmente nos últimos anos, sobre gentrificação no Brasil. O termo parece ter se tornado lugar comum entre estudiosos do urbano e por vezes parece ser utilizado sem muito rigor científico, para referência a fenômenos distintos ocorridos em áreas alvo de políticas públicas de desenvolvimento ou incremento de infraestrutura urbana. No entanto, os contornos do conceito de gentrificação e a problematização de sua aplicação no cenário urbano brasileiro são pouco explorados nos textos sobre o tema, o que vem permitindo um certo grau de distorção do conceito e dos fenômenos a ele submetidos. O presente artigo pretende ocupar esta lacuna ao realizar um estudo conceitual mais detalhado e uma problematização do cenário geral da aplicação do conceito de gentrificação, passando por um breve panorama latino americano e chegando ao Brasil a partir da análise de algumas experiências em cidades brasileiras, para então concluir sobre os limites e potencialidades do conceito na realidade nacional. A metodologia utilizada se baseia em análise bibliográfica e empírica a partir de dados obtidos de forma indireta.

Palavras-chave: gentrificação, políticas públicas, desenvolvimento urbano, capitalismo, espaço urbano.

\begin{abstract}
Particularly within the past few years, much has been spoken about gentrification in Brazil. The expression appears to have turned into commonplace among scholars dedicated to studying the urban phenomenon and, occasionally, is used without scientific accuracy referring to different phenomena occurring in areas subject to redevelopment or increment of urban infrastructure. However, the outlines of the gentrification concept and the problematization of its application in the Brazilian urban scenario are little addressed by relevant papers, which is allowing a certain level of distortion of the concept and the phenomena subject to it. This paper seeks to fill this gap in conducting a more detailed conceptual analysis and a problematization of the general scenario of the gentrification concept, going through a brief latin-american overview and Brazil taking into consideration the analysis of some experiences in Brazilian cities, in order to present a conclusion regarding the limits and potentialities of the concept within the national reality. The methodology used is based on a bibliographic and empirical analysis of indirectlyobtained data.
\end{abstract}

Keywords: gentrification, public policies, urban development, capitalism, urban space.

\footnotetext{
${ }^{1}$ Doutoranda em Planejamento Urbano e Regional pela Universidade Federal do Rio de Janeiro (UFRJ). Pesquisadora do Laboratório de Estudo das Transformações do Direito Urbanístico Brasileiro . Membro da Red de Estudios sobre Desarrollo Urbano Sustentable de Latinoamérica y el Caribe. E-mail: tarcylafidalgo@gmail.com
} 


\section{INTRODUÇÃO}

Nos últimos anos, muito se tem falado na literatura sobre o fenômeno da gentrificação no Brasil. Tal fenômeno é invocado para explicar processos diversos, baseados em projetos e locais distintos, muitas vezes sem uma reflexão mais apurada sobre seu efetivo cabimento nestas situações.

Neste cenário, há uma percepção de que o termo gentrificação ganhou diversos "sinônimos", como remoção branca, elitização, enobrecimento, etc., termos muitas vezes mais antigos, utilizados em debates e textos de forma equiparada à gentrificação ${ }^{2}$, para se referir a um plexo de fenômenos diversos que vão desde as mudanças de frequentadores em determinada localidade até a remoção de moradores para intervenções de embelezamento urbano, sem maiores reflexões sobre os sentidos individuais destas referências e sua adequação à realidade fática a qual pretende-se subsumi-las. Mais que um conceito, a palavra "gentrificação" expressa um processo social, econômico e espacial quevai muito além da saída de moradores ocasionada pelas forças do capital, ou ainda da reforma de espaços físicos na cidade.

De fato, trata-se de processo socioespacial e econômico, traduzido em conceito, que vem sendo discutido no âmbito internacional há mais de 50 anos e que acumulou neste tempo um grande plexo de significados, aplicações, além de uma indiscutível complexidade teórica e empírica. Nestes mais de 50 anos, assistiu-se à globalização dos processos de gentrificação, que passou a ser reconhecido em cidades de diversos continentes, com as mais diversas estruturas econômicas e sociais. Esta globalização do fenômeno promoveu a ampliação do conceito visto que os processos de gentrificação são altamente sensíveis às condições específicas de cada área por eles afetada.

Após buscar compreender o processo e o conceito de gentrificação nos dias atuais, será realizada uma breve incursão sobre os parâmetros adquiridos por este conceito na América Latina, a fim de contextualizar e finalmente voltar o foco do estudo para o Brasil, sua relação com o conceito e suas experiências mais emblemáticas sobre processos usualmente

\footnotetext{
${ }^{2}$ Vide neste sentido:

RODRIGUES, Sérgio. Gentrificação, o que é isso?. Disponível em: <http://veja.abril.com.br/blog/sobrepalavras/gentrificacao-o-que-e-isso/>. Acesso em 12 de abril de 2017.

CBN. Especulação faz moradores se mudarem de favelas da Zona Sul do Rio. Disponível em: < http://cbn.globoradio.globo.com/rio-de-janeiro/2014/04/17/ESPECULACAO-IMOBILIARIA-FAZMORADORES-SE-MUDAREM-DE-FAVELAS-DA-ZONA-SUL-DO-RIO.htm>. Acesso em 12 de abril de 2017. ASSIS, Aramis. Gentrifica...o quê? Gentrificação. Disponível em:< http://redesdamare.org.br/blog/noticias/gentrifica-o-que-gentrificacao/>. Acesso em 13 de abril de 2017.
} 
classificados como gentrificação, com o objetivo de problematizar a utilização indiscriminada do termo "gentrificação" por aqui, sem a devida observação das peculiaridades de cada processo e a análise de seu real cabimento na categoria conceitual ora estudada.

\section{CAPITALISMO E GENTRIFICAÇÃO}

Não é possível tratar do conceito de gentrificação sem resgatar as relações entre capitalismo e espaço urbano. Isto porque, historicamente, as dinâmicas territoriais e populacionais, inclusive aquelas referentes aos movimentos de gentrificação, identificados a partir da década de 60 do século XX, têm relação íntima com as necessidades do capital nas mais diversas regiões do mundo. Na verdade, as cidades, como as conhecemos hoje, são um retrato da dinâmica capitalista, estabelecida com maior ênfase desde a revolução industrial.

Capitalismo e espaço urbano se relacionam intimamente, de diversas formas, nos diversos períodos históricos. Aqui a análise será focada em duas destas relações, envolvendo os excedentes de capital, a nova divisão social do trabalho entre as cidades e a urbanização, que se mostram como ponto central para a compreensão da gentrificação.

Conforme destacado pela teoria marxista, o capitalismo fundamenta-se na eterna busca de mais-valia que, por sua vez, para ser produzida depende da obtenção de excedentes de produção. Estes excedentes, pela lógica da concorrência capitalista, tendem a se expandir cada vez mais gerando, de tempos em tempos, a necessidade de busca de esferas rentáveis para a absorção deste "excedente excessivo" de capital.

Um destes locais aptos a receber os excedentes de capital e rentabilizá-los é o urbano. As atividades de redesenvolvimento urbano, ligadas às mudanças nas necessidades dos citadinos ou à reconstrução do território das cidades, é fundamental para a absorção dos excedentes do capital, evitando o estabelecimento de uma crise pelo excesso de acumulação (HARVEY, 2014:30).

Ocorre que o investimento em infraestrutura urbana também tem seus limites de rentabilidade. Por exemplo, a melhoria de bairros pobres, ainda que subsidiada pelos governos, tende a produzir menos lucro que as melhorias realizadas em bairros ricos, seja porque 0 investimento do capital em meios de consumo coletivos pressupõe uma redução dos lucros, seja pela capacidade da população residente responder às melhorias com a valorização imobiliária da área. Além disso, há um limite de melhorias a serem feitas nas cidades, que teoricamente esgotaria esta fonte de absorção de excedentes em determinado momento. 
Com base nesta premissa e considerando que o "excesso de excedentes" é um problema crônico do capitalismo, surgem as ideias de transformação urbana no lugar das meras melhorias, com a "destruição e reconstrução criativa" das cidades, o que torna o urbano e seus processos de redesenvolvimento uma fonte quase que inesgotável de absorção de excedentes (HARVEY, 2014:49).

Aqui chegamos ao ponto de contato mais nítido entre a dinâmica capitalista e a gentrificação, exatamente nas renovações criativas das cidades e no desenvolvimento de infraestruturas como fontes de absorção de excedente de capital. Trata-se da absorção do capital por meio do redesenvolvimento urbano.

Os movimentos de renovação ou revitalização de áreas específicas nas cidades (nomenclaturas utilizadas para exaltar oss aspectos positivos e esconder as consequências negativas dos processos de redesenvolvimento), bem como o desenvolvimento de infraestrutura urbana, têm por consequência, em geral, de forma desejada ou não, o desalojamento de população, seja de forma direta, por meio de desapropriações e remoções, seja de forma indireta, pelas mudanças de padrão de moradia e consumo nestas áreas com a nova forma de urbanização. Quanto a este último aspecto, cabe destacar que os processos de redesenvolvimento são condição necessária mas não suficiente para o desalojamento indireto da população, que depende ainda de outros fatores sociais, econômicos e políticos para se concretizar, conforme se verá mais adiante.

Outra relação, de viés menos economicista, que se estabelece entre capital e espaço urbano e que merece ser aprofundada para o estudo da gentrificação é a nova divisão social do trabalho entre as cidades capitalistas e suas implicações socioeconômicas (HAMNETT, 1991, p. 174).

A nova divisão social do trabalho entre as cidades capitalistas surge com as mudanças para um estágio de capitalismo avançado, em um regime de acumulação flexível. Estas mudanças levaram à emergência das cidades globais, isto é, cidades que concentram capitais culturais e intelectuais únicos, funções de controle e comando das atividades econômicas. Estas atividades, por sua vez, encontram-se cada vez mais dispersas em cidades das mais diversas regiões do globo, em posição hierárquica inferior às das cidades globais, mas com vantagens em termos de custo de alocação e produção.

A reestruturação da hierarquia urbana promovida por esta nova divisão social gerou a necessidade de uma reestruturação interna nas cidades, de modo a se alocarem nesta nova hierarquia, sempre visando às melhores posições. 
Este cenário de reestruturação urbana não se dá apenas no aspecto físico das cidades, mas também passa por uma reestruturação das classes sociais, da produção e do consumo nos centros urbanos.

Em diversas cidades assistimos ao surgimento de uma "nova classe social", constituída por profissionais pertencentes a novos ramos profissionais ligados diretamente às atividades altamente especializadas desenvolvidas nas cidades centrais. Estes indivíduos tendem a preferir os centros para fixar sua moradia, pois estas regiões passam a concentrar capitais simbólicos e intelectuais próprios, além das atividades profissionais deste grupo. (LEY, 1986, p. 129)

É neste contexto de reestruturação urbana que produz cidades altamente fragmentadas - no sentido de disjunção do tecido social -, que se insere a gentrificação como processo de elitização de determinadas áreas com a substituição da população tradicional por moradores com maior poder aquisitivo a partir de seu redesenvolvimento, com incremento de infraestrutura e/ou requalificação urbana.

Assim, podemos perceber que a dinâmica capitalista, que sempre interferiu de forma direta no âmbito urbano, nos últimos anos, com a passagem para o capitalismo avançado 3 e as mudanças por ela acarretadas no papel e na hierarquia das cidades, passou a ditar o ritmo de reconstrução destas, com papel de destaque para os processos de gentrificação tidos como inevitáveis e até mesmo desejáveis pelo capital.

\section{O CONCEITO DE GENTRIFICAÇÃO}

O termo gentrificação surge pela primeira vez na década de 60 do século XX, na obra de Ruth Glass, em referência às mudanças ocorridas na cidade de Londres, especialmente nas regiões habitadas pela classe operária, como Islington.

A palavra gentrification, incorporada em nosso vocabulário como gentrificação, surge de uma observação feita por Glass do processo de renovação de certas áreas da capital britânica na década de 60 do século XX, com a substituição de moradores mais pobres por outros integrantes de classes mais altas. Em suas palavras: "One by one, many of the working class quarters have been invaded by the middle class - upper and lower ... Once this process of 'gentrification' starts in a district it goes on rapidly until all or most of the working class

\footnotetext{
${ }^{3}$ Aqui entendido como a etapa do capitalismo caracterizada pela globalização e o predomínio de ativos financeiros na dinâmica da produção e circulação de capital. Neste cenário, as cidades são hierarquizadas e transformadas elas próprias em objeto do capital, seja como mercadoria ou como estrutura para a circulação em uma dinâmica de crescente financeirização.
} 
occupiers are displaced and the whole social social character of the district is changed" (GLASS, 1964, p.27). Na definição dada por Glass para a gentrificação, esta corresponderia ao conjunto de dois fatores observados em determinada área: (i) um processo de desalojamento de residentes pertencentes ao proletariado, substituídos por grupos oriundos de classes sociais mais altas e (ii) um processo de reabilitação física destas áreas.

Desde então, o conceito de gentrificação foi problematizado e aplicado a diversas situações de revitalização urbana pelo mundo, incluindo novas formas de substituição social no território, novos atores e novos espaços (RÉRAT, 2010, p. 336), dando origem a disputas teóricas e práticas sobre seu conteúdo. Estas teorias, embates e novas formas de apresentação do fenômeno serão apresentadas no presente artigo.

\section{As duas teorias principais sobre o conceito de gentrificação}

Ao longo das décadas, desde o surgimento do conceito, duas teorias se destacaram na tentativa de compreender o fenômeno da gentrificação: a dos humanistas liberais, que destacam o papel da escolha individual, da cultura e do consumo, e a dos marxistas estruturalistas, que destacam o papel do capital, das classes sociais, da produção e da demanda (HAMNETT, 1991, p.175).

A primeira teoria tem como expoente o geógrafo David Ley, enquanto que a segunda é representada pela famosa produção acadêmica sobre o tema de Neil Smith. Embora as teorias se apresentem como opostas, desejamos apresentá-las neste trabalho como complementares, duas facetas fundamentais para a compreensão deste fenômeno tão complexo que é a gentrificação.

Para Ley (1981, p. 127), o estudo da gentrificação deve passar pela compreensão de três aspectos fundamentais do contexto sócio-econômico no século XX: (i) o declínio do uso maciço de mão de obra na produção industrial e o desenvolvimento e importância da tecnologia; (ii) o papel ativo dos governos característico das sociedades pós-industriais; (iii) a emergência de uma nova classe social, como resultado das transformações sociais, econômicas e da divisão social do trabalho, com gostos e padrões de consumo peculiares a serem atendidos.

Além da atenção ao contexto econômico-social, que explicaria o surgimento dos "gentrificadores", pertencentes a uma nova classe econômica com valores próprios, Ley (198:132) dá ênfase à questão cultural na compreensão do fenômeno da gentrificação, 
afirmando que os modos de vida, a diversidade de atividades culturais e a arquitetura dos ambientes são fatores importantes que influem nas decisões locacionais dos indivíduos, especialmente quanto ao seu retorno às áreas centrais e históricas das cidades.

Com a ênfase dada à cultura, e à escolha dos indivíduos pertencentes a determinado grupo social, a teoria desenvolvida por Ley se foca nos aspectos de demanda das construções gentrificáveis e não na sua oferta, como Smith e sua análise marxista do fenômeno.

Smith, em uma suposta oposição à teoria de Ley, adota como ponto de partida e de ênfase de sua teoria ao movimento do capital no espaço urbano, mais especificamente no aspecto da produção de moradia capitalista que, em sua visão, daria ensejo ao processo de gentrificação (1979:546).

A partir da ênfase dada à produção, Smith desenvolve sua teoria de "rent-gap" como principal fonte de explicação para o fenômeno da gentrificação. Esta teoria, em apertada síntese, consiste na explicação da gentrificação por uma dinâmica de investimento e desinvestimento urbano relacionada à variação do preço da terra em diferentes áreas da cidade.

Smith afirma, tendo como fonte de análise as cidades norte-americanas, que o movimento de suburbanização experimentado por estas a partir da segunda metade do século $X X$, fez com que as áreas centrais fossem ocupadas por classes de menor poder aquisitivo, que não conseguiam recursos para se mudar para os subúrbios, levando à deterioração e desvalorização de tais áreas. No entanto, apesar do baixo valor de venda dos imóveis nestas regiões, seu potencial de valorização pela localização podia ser definido como elevado. Trata-se de "um diferencial (rent gap) entre a atual renda da terra capitalizada pelo uso presente (deteriorado) e a renda da terra potencial que poderia ser capitalizada pelo 'mais elevado e melhor' uso da terra em função de sua localização centralizada". (SMITH, 2007)

Deste modo, passa a ser interessante para o capital, em sua eterna busca por investimentos atrativos para a alocação de seus excedentes, investir nestas áreas por meio de processos de renovação ou revitalização, para posterior venda a valores elevados, se apropriando do lucro oriundo do rent gap (SMITH, 1979:547). Ocorre que estas transformações, visando à valorização do território, implicam a saída da população que originalmente habitava aquelas áreas e a entrada de grupos de maior renda, que garantem maior retorno de lucro aos investidores imobiliários, constituindo então o processo de gentrificação.

Para Smith e sua teoria, portanto, o papel do consumo, da demanda, do pertencimento a determinado grupo social e da escolha pessoal fica relegado a segundo plano quando se trata 
de gentrificação. Não que ele negue o papel destas variáveis na compreensão plena do processo, mas defende que sem o mecanismo de rent-gap e as disposições de produção capitalista da moradia, não haveria gentrificação.

O ponto de contato inicial das definições formuladas por ambas as teorias é que a gentrificação envolveria uma mudança na composição social da área e seus moradores e também uma mudança na natureza do estoque imobiliário.

No entanto, as duas teorias partem de pontos distintos para compreender o fenômeno da gentrificação e ambas, consideradas individualmente, parecem falhas em algum aspecto. Enquanto Ley, ao colocar o consumo, a cultura, o pertencimento a determinado grupo social e as preferências individuais em primeiro plano parece falhar em explicar a generalização do fenômeno, Smith e sua análise econômica, baseada nas interações entre o capital e o urbano, parece falhar na explicação dos locais exatos em que a gentrificação se verifica, aspecto que depende da consideração das preferências individuais, do consumo e da cultura. Sem a atratividade econômica os investimentos não se realizam e a gentrificação não ocorre, mas sem as mudanças culturais e comportamentais de uma nova classe de citadinos que levam a uma alteração das preferências individuais de localização na cidade também não.

A importância das mudanças sociais e da escolha individual foi, inclusive, reconhecida por Smith posteriormente, mas ainda relegada a segundo plano diante dos processos econômicos urbanos que levariam à gentrificação. (SMITH, 2007)

É importante reconhecer a complementaridade das teorias expostas para uma compreensão mais ampla do fenômeno da gentrificação. Antes de utilizar o conceito, é fundamental ter noção deste embate teórico que o envolve e da complementaridade dos elementos que cada uma das teorias traz para uma visão mais completa da gentrificação.

\section{As "novas formas de gentrificação"}

Nos últimos anos, as pesquisas sobre gentrificação têm problematizado o termo por meio da indicação de casos e situações que, apesar de não conterem todos os requisitos do conceito como tradicionalmente entendido, se encaixariam no plexo conceitual da gentrificação, alargando suas possibilidades e significados.

Uma das "novas formas de gentrificação" apontadas pelas pesquisas sobre o tema, em especial por Zukin (1995) se refere às transformações do espaço público que, uma vez reestruturados urbanística e arquitetonicamente, bem como alvo de novas normas de usos 
explícitas ou implícitas, acabam contribuindo para a exclusão de seus frequentadores habituais e sua substituição por grupos com maior poder econômico.

Nesta "gentrificação de espaços públicos", ocorre uma filtragem social, via de regra com protagonismo do Estado. Muitas vezes as alterações nos espaços públicos que iniciam ou consolidam os processos de gentrificação se relacionam com o interesse na alteração do gradiente de valorização do entorno, em consonância com as duvidosas parcerias entre o público e o privado características deste início de século. Apesar das peculiaridades, estes processos foram incluídos em um conceito estendido de gentrificação pela substituição de grupos sociais frequentadores destes espaços.

Outra forma nova do fenômeno da gentrificação apontada por alguns autores é a "gentrificação comercial", que consiste no pioneirismo dos comerciantes de certas áreas sobre seu processo de redesenvolvimento. Os autores que utilizam esta forma de gentrificação (VAN CRIEKINGEN; FLEURY, 2006) afirmam se tratar de uma iniciativa dos comerciantes de determinada área que remodelam seus comércios atraindo um novo tipo de clientela, com maior poder aquisitivo, que passa a frequentar o local.

Há ainda a chamada "gentrificação de novas construções", que consistiria na construção de moradias de alta classe em áreas centrais e industriais. Esta forma de gentrificação, utilizada por Davidson e Lees (2005) é a mais próxima do conceito clássico, se diferenciando na questão da retirada de moradores de classe mais baixa que habitariam o local anteriormente. Neste caso, como as construções são novas, em terrenos que não eram utilizados para residências, este traço se torna mais sutil, embora ainda presente em determinadas localidades especialmente na forma de remoção indireta, pelos novos padrões de consumo e moradia estabelecidos no local e muitas vezes em seu entorno.

Estas "novas formas de gentrificação", se analisadas à luz das disputas teóricas sobre o conceito, podem ser entendidas como "estudos de casos" com peculiaridades na fase inicial do processo, que nos casos apresentados é iniciado por atores distintos, como o Estado (no espaço público) e os comerciantes. Quanto à "gentrificação de novas construções", parece ser apenas um caso de maior facilidade para os investimentos do capital imobiliário na região, visto que os terrenos se encontravam fora do mercado imobiliário. Apesar disso, a classificação destes processos como novas formas de gentrificação é controvertida, com diversos autores se posicionando de forma contrária a tal classificação por se tratarem de casos que não possuiriam as características definidas pelo conceito de gentrificação clássico. 
Tem se verificado mais recentemente uma forte defesa da ampliação do conceito de gentrificação para que possa englobar processos que, embora não correspondentes com exatidão ao conceito clássico, tenham relação com o contexto e as consequências conhecidas da gentrificação nas cidades. A defesa desta necessidade se justifica pela globalização do fenômeno e pelas particularidades assumidas pelo processo em cidades com contextos sociais e econômicos diferenciados, como no caso das cidades latino-americanas, por exemplo.

Na literatura sobre o tema, percebe-se uma tendência à ampliação do conceito de gentrificação com alguma relativização dos fatores tidos como indispensáveis para sua caracterização a fim de abarcar processos ocorridos em contextos diferentes e a complexidade trazida pela globalização do fenômeno.

Esta ampliação conceitual, no entanto, deve ser vista com cautela na medida em que, apesar de ser importante a atualização de conceitos como o de gentrificação - especialmente em um âmbito de aplicação tão dinâmico quanto o urbano -, a manutenção de sua utilidade parece depender da determinação de parâmetros mínimos, aptos a constituir uma espécie de núcleo rígido para o fenômeno que se pretende abarcar com a utilização do conceito. A construção deste "núcleo rígido", que neste caso parece girar em torno de dois elementos, as intervenções físicas e a substituição de população ${ }^{4}$, se mostra fundamental para que se possa classificar tal e qual processo como gentrificação, sob pena de se trabalhar sobre uma categoria vazia de significado e, em última análise, sem utilidade.

\section{A gentrificação na América Latina}

Conforme até aqui demonstrado, a gentrificação enquanto processo e enquanto conceito surgiu primeiramente no hemisfério norte, notadamente na Europa e na América do Norte, ainda que assumindo contornos diversos nestes locais. Nas últimas décadas muitos pesquisadores se dedicaram a analisar os processos de redesenvolvimento vivenciados na América Latina sob o paradigma da gentrificação construído no e para o hemisfério norte, sem, no entanto, considerar as peculiaridades da região e seu contexto.

\footnotetext{
${ }^{4} \mathrm{O}$ termo neste caso deve ser entendido além de uma leitura dicotômica e reducionista entre pobres e ricos, com foco nas alterações socioespaciais que tornem o local hostil aos antigos moradores e frequentadores, com um certa independência do seu contexto econômico.
} 
Apesar das diferenças de histórico político e econômico, a região pode ser vista como um todo pelas suas características e especialmente por sua posição, ao longo dos séculos, na divisão social do trabalho capitalista.

De fato, durante muito tempo a América Latina foi vista, no cenário econômico mundial, como uma região fornecedora de matérias-prima e importadora de tecnologia e produtos industrializados complexos, o que a deixava em posição extremamente desfavorável em termos comerciais.

No capitalismo avançado, as cidades latino-americanas experimentaram processos mais ou menos intensivos de redesenvolvimento, preparando-se para o desempenho de papéis diversos na nova hierarquia urbana: algumas cidades como São Paulo, Cidade do México e Buenos Aires se tornaram polos de distribuição e transferência de capital enquanto outras acabaram entrando na hierarquia ocupando posições de menor destaque (BETANCUR, 2014).

Estes processos de redesenvolvimento se iniciaram na década de 90 do século XX e propiciaram a reunião de fatores necessários para a ocorrência de gentrificação: (i) interesse do capital em investir no redesenvolvimento urbano destas cidades; (ii) existência de áreas com importante diferencial entre a renda da terra atualmente percebida e a potencial após investimento e (iii) existência de potenciais gentrificadores, pertencentes a nova classe social surgida com o capitalismo avançado.

Importante destacar que estes processos de redesenvolvimento não partiram necessariamente de iniciativa dos países e cidades latino-americanas, sendo muitas vezes impostos por agentes internacionais de forma direta (UNESCO, FMI, Banco Mundial, etc) ou indireta - pela imposição de condições estruturais, econômicas e sociais para que as cidades periféricas ingressassem na hierarquia urbana e fossem capazes de atrair investimentos. Essas influências tornam clara a ligação entre as escalas global e local nos processos de gentrificação localizados na América Latina.

Apesar disso, os processos de gentrificação desenvolvidos na América Latina se mostraram bastante diversos daqueles reconhecidos na Europa e na América do Norte, seja pela menor presença de potenciais gentrificadores, dado o papel secundário desenvolvido por estas cidades na hierarquia urbana, seja pelo rent gap existente nas áreas centrais ser prejudicado pela permissividade dos governantes e pela extensão dos assentamentos subnormais instalados nestas regiões e atualmente de difícil remoção, ou ainda pela maior dependência da iniciativa estatal, com políticas públicas e investimentos para tocar os processos por meio dos planejamentos estratégicos. 
Além disso, na América Latina os processos de gentrificação, via de regra, apresentam relação direta com a exploração do patrimônio histórico das cidades em que se instalam, sendo consequência, muitas vezes, de projetos de "revitalização" destas áreas. De acordo com Salinas Arreortua (2013:288), o patrimônio histórico é um catalisador do processo de gentrificação latino-americano, a partir do qual se desenvolve o papel os governos em um modelo de gestão urbana empresarial (HARVEY, 2014).

O autor destaca ainda três tendências principais assumidas pela gentrificação latinoamericana: (i) transformações sociais na imagem urbana - com o objetivo de atrair investimentos e pessoas pertencentes a grupos sociais com maior poderio econômico, os governos investem altas somas de dinheiro na expulsão de comerciantes e moradores de baixa renda a fim de embelezar as áreas centrais da cidade; (ii) intervenções no patrimônio histórico projetos de recuperação ou resgate do patrimônio histórico que, na verdade, encobrem e alimentam medidas de marketing urbano; e (iii) intervenções privadas nos centros históricos as intervenções governamentais nas regiões históricas das cidades latino-americanas, bem como eventuais vantagens tributárias e urbanísticas fornecidas pelos governos, incentivam a entrada do capital privado nestas regiões por meio de investimentos em novas construções, hotéis e construção de infraestrutura para classes mais abastadas, o que acaba promovendo de forma mais contundente a gentrificação nestas áreas.

Todas estas condições dão uma nova face à gentrificação na América Latina, que serve de cenário para uma análise mais profunda sobre a utilização do conceito no Brasil e seus casos mais acionados conforme se passa a expor.

\section{GENTRIFICAÇÃO NO BRASIL}

Os processos de gentrificação no Brasil seguem as características latino-americanas já apresentadas, como o forte apelo ao patrimônio cultural das cidades, a dependência de investimento (principalmente inicial) e de engajamento estatal, e o menor impacto dos processos gentrificadores pelos fatores já expostos neste artigo quando da análise do panorama latino-americano.

Para a análise deste processo, destacaremos alguns exemplos de processos classificados como gentrificação em curso ou já estabelecidos em cidades brasileiras. As análises destes casos terão por base dados indiretos, obtidos por meio de revisão bibliográfica sobre o tema nos limites territoriais propostos. Destaque-se que não se trata de trabalho de campo ou de 
dados obtidos por esta autora, mas sim da análise de processos concretos, ocorridos ou em curso no Brasil, e classificados como casos de gentrificação pela literatura.

\section{Salvador - Bahia}

$\mathrm{Na}$ cidade de Salvador, a área mais emblemática referente a processos de redesenvolvimento urbano e gentrificação é a do Pelourinho. A região do Pelourinho, situada na cidade alta, foi o centro da aristocracia colonial durante o período no qual Salvador foi a capital da então colônia, Brasil. Trata-se de região muito rica no que se refere à arquitetura e ao patrimônio histórico contido nas ruas de chão do tipo "pé de moleque".

Com a transferência da capital para o Rio de Janeiro no final do século XVIII, o processo de deterioração do Pelourinho se intensificou "em função da especulação imobiliária fora de seus limites e das obras públicas advindas do nascimento do urbanismo moderno" (NOBRE, 2003, p.04).

O processo de decadência seguiu em curso até o final do século XX, com a área já famosa pela degradação urbanística-habitacional e pela violência, datando de 1991 o primeiro projeto de revitalização efetivamente implementado na região. Este projeto foi financiado pelo governo do estado da Bahia com o objetivo de restaurar as edificações da região, melhorar o espaço público e a infraestrutura local, sob a justificativa de recuperação da região do cenário de forte degradação e da associação da área à violência e prostituição.

O projeto foi iniciado em 1992, atingindo uma área total de 104.142 m que incluía outros bairros além do Pelourinho (BONFIM, 2007) e contou com a remoção de muitos moradores antigos da região ${ }^{5}$, que antes era marcada predominantemente por habitações populares precárias. Como resultado, a área se tornou primordialmente um centro turístico e comercial com uma pequena parcela de edifícios residenciais destinados à população de classe média (SAMPAIO, 2007, p. 32).

Na região do Pelourinho, pelo baixo percentual de imóveis destinados à residência após o processo de revitalização, poderia-se perceber a presença do que se chama de

\footnotetext{
${ }^{5}$ Segundo NOBRE (2015), no ano de 1995 85\% das famílias da região do Pelourinho tinham firmado acordo para receber uma compensação, algo em torno de 900 dólares, e deixar suas residências. Ainda segundo ele, com base em dados do IBGE, houve uma "perda brutal de $67 \%$ da população do Centro Histórico (distritos da Sé e Passo), caindo de 9,8 para 3,2 mil habitantes, enquanto que os arredores (distritos de Nazaré, Santana e São Pedro) perderam 33\% da população residente, diminuindo de 54,6 para 36,5mil habitantes".
} 
"enobrecimento de visitação" (BIDOU-ZACHARIASEN, 2006), que sugere um processo de gentrificação baseado no papel do turismo e no foco comercial das edificações da área afetada.

Neste caso, não se percebe de forma significativa uma substituição de moradores, até porque o número de imóveis destinados à residência na região foi substancialmente reduzido ${ }^{6}$, mas sim de frequentadores, que passam a ser predominantemente pertencentes a grupos de maior poderio econômico, contribuindo decisivamente para o rompimento completo do tecido social estabelecido anteriormente na região.

Portanto, em um processo iniciado pelo poder público e baseado fortemente na exploração do patrimônio cultural da cidade, vemos um exemplo do que seria um processo de gentrificação mais ligado à ambiência e à frequência do local do que aos seus residentes. Este tipo peculiar de gentrificação seria verificado com frequência no Brasil e é potencial alvo de discussão teórica sobre sua adequação ao conceito de gentrificação, dada sua baixa relação com a substituição de residentes nas áreas afetadas, encarada por muitos, aos quais nos filiamos, como elemento sine qua non para a aplicação do conceito, conforme visto anteriormente.

Apesar da não adequação ao conceito estrito de gentrificação, conforme apresentado anteriormente, trata-se de processo com resultados claros no sentido de substituição dos frequentadores do local, excluindo os moradores tradicionais de baixa renda para privilegiar turistas e frequentadores com maior poderio econômico.

\section{Recife - Pernambuco}

O projeto de redesenvolvimento mais emblemático da cidade de Recife é o da revitalização do Bairro Recife, uma pequena ilha portuária que foi o núcleo primitivo da cidade ainda no período colonial. Esta região, primeiro local a receber os portugueses no que viria a ser a cidade de Recife, sofreu ainda uma forte influência holandesa - quando da invasão e instalação que resultou inclusive na implantação do primeiro plano urbanístico da cidade - e francesa - influência da reforma sofrida pela região em 1910 seguindo uma tendência no país de modernização de suas principais cidades.

\footnotetext{
${ }^{6}$ Ainda de acordo com NOBRE (2015), a maioria dos imóveis da região do Pelourinho teria sido convertida para uso comercial, chegando tal uso ao percentual de $64,8 \%$ do total dos imóveis da região, enquanto que apenas $16 \%$ deles teriam permanecido com o uso residencial.
} 
Marcada por décadas de decadência, a região foi alvo de um projeto de revitalização com um propósito claro de restauração do patrimônio histórico-cultural articulado com a ideia de intervenção urbana como empreendimento (LEITE, 2002, p.117), já dentro de uma lógica financeirizada de redesenvolvimento urbano. O projeto teve início em 1993, apenas um ano depois da implantação do projeto de revitalização do Pelourinho - Salvador, anteriormente estudado.

O plano de revitalização do Bairro Recife tinha três objetivos principais: (i) transformar a área em um polo de serviços, cultura e lazer; (ii) torná-la um espaço público de lazer e diversão; (iii) transformá-la em um centro de atração turística com base na recuperação e valorização de seu patrimônio histórico e cultural, com claros interesses econômicos

Mais uma vez a exploração econômica do patrimônio histórico esteve presente em um projeto de redesenvolvimento, que teria levado a um processo de gentrificação, no Brasil. Este projeto teria ainda trazido consigo o fenômeno da "espetacularização da cultura", destacado por Rogério Proença Leite (2010:119) e a construção de uma imagem histórica e cívica no local, típica do marketing urbano para a valorização do espaço. De fato, ainda de acordo com Leite (2002, p. 130), alguns moradores da cidade veem no Bairro Recife um local de retorno e de orgulho das raízes pernambucanas.

Um dos resultados do plano de revitalização foi a reforma dos casarios do Bairro que passaram a abrigar restaurantes, bares e casas noturnas, transformando as suas ruas em um agitado ponto de encontro, que passou a atrair, como no Pelourinho, um público de classe média e alta, além de turistas, que não costumava a frequentar o local.

No Bairro Recife, como antes visto na região do Pelourinho - Salvador, apesar de não estar comprovada a presença dos elementos constitutivos do núcleo do conceito de gentrificação, especialmente no que se refere à substituição de moradores - o que não nos permitiria classificá-lo como tal, em que pese os posicionamentos contrários já exaustivamente expostos neste trabalho - há sem dúvidas uma transformação espacial, social e econômica baseada na substituição dos frequentadores por meio da nova ambiência criada para o local.

Na verdade, os processos de transformação territorial experimentados pela região do Pelourinho, em Salvador, e do Bairro Recife, em cidade homônima, tem muitas semelhanças que podem avalizar a ideia de um mesmo processo de transformação socioespacial tendo por características a revitalização de áreas possuidoras de elevado valor histórico e cultural, com escusos fins econômicos, levando a um processo de substituição de frequentadores. 
Apesar das controvérsias sobre o tema acreditamos que não se está diante de um cenário de gentrificação, mas sim de um movimento de apropriação urbana pelo capital com traços próprios e que merece aprofundamento pelos estudiosos do urbano.

\section{Rio de Janeiro}

A cidade do Rio de Janeiro, capital da República até 1960, teve e tem até os dias de hoje um processo peculiar de desenvolvimento urbano, em muito marcado pelas mudanças de seu papel na hierarquia urbana nacional e internacional.

Nos últimos anos, a cidade passou por um processo acelerado de modificações urbanas motivado de forma direta principalmente pelos "megaeventos", que tiveram como sede a cidade e pelo alinhamento de instâncias governamentais em um arranjo colaborativo inédito. Além desta motivação direta há um movimento maior de inserção do Rio de Janeiro na nova hierarquia urbana global, no contexto do capitalismo avançado, já explorada neste trabalho. Esta motivação "indireta" exige que as cidades construam um certo número de infraestrutura mínimas, além de se adequarem a padrões internacionais urbanos.

Neste contexto, embora se possa falar de diversas áreas da cidade alvo de projetos de redesenvolvimento urbano que podem levar a um cenário de gentrificação, vamos destacar como exemplo, pelo seu caráter emblemático em relação às políticas públicas urbanas atuais no Rio de Janeiro, o caso do "Porto Maravilha", projeto de renovação urbana que vem sido levado a cabo na região portuária da cidade (CARLOS, 2010).

A região portuária do Rio de Janeiro inicia seu desenvolvimento a partir do séc. XVIII como local de moradia e comércios indesejáveis na região central, mas que necessitavam de sua proximidade, como os cortiços, com a concentração de mão de obra para as atividades realizadas no centro da cidade, e o comércio de escravos. Ali também teve origem a mais célebre favela carioca, e uma das mais antigas, no Morro da Providência, no final do século XIX.

Após um período de maior atenção dedicada pelas autoridades públicas devido aos investimentos no porto que ali se instalara, a região voltou ao esquecimento e à degradação a partir da década 60 do século XX, com a transferência da capital para Brasília e a queda na captação de recursos pela cidade.

Desde então, foram produzidos inúmeros projetos para o redesenvolvimento, por meio da revitalização e renovação urbana da região, sem que, no entanto, tenham saído do papel, 
especialmente pela falta de recursos e de articulação política com os demais entes da federação, proprietários de expressiva área da zona portuária carioca.

No entanto, somente na última década, somando a remodelação da cidade oportunizada pelos "megaeventos" esportivos e a articulação entre governos municipal, estadual e federal, foi posto em prática um projeto de revitalização da região portuária do Rio de Janeiro, denominado de projeto "Porto Maravilha".

Tal projeto foi estruturado em forma de parceria entre o poder público e instituições privadas, por meio de uma operação urbana consorciada, instrumento jurídico que permitiria, em tese, a instalação de infraestrutura na região pela iniciativa privada, com baixo ou nenhum custo para o poder público, com a contrapartida da exploração da área pelos investidores privados por determinado período após as obras. Para gerenciar esta parceria foi criada uma empresa concessionária, a Porto Novo $S / A^{7}$, que ficou responsável por toda a gestão da região, como manutenção de ciclovias, recolhimento de lixo, iluminação pública e sinalização do trânsito, até o ano de 2026, recebendo remuneração por estes serviços.

As novas estruturas pensadas para o porto são voltadas para a atração de turistas e investimentos nacionais e internacionais, além das classes média e alta carioca (GAFFNEY, 2013:11), excluindo os moradores originários da região que em uma medida considerável foram removidos para outras áreas da cidade $^{8}$. A beleza dos projetos e das imagens, associada ao forte marketing urbano que se apresenta na região, cria um certo consenso sobre os efeitos positivos das obras, que dificulta a apresentação de uma avaliação crítica do projeto.

Todas estas estruturas pensadas e construídas na região formam um corredor de valorização que favorece a gentrificação da área em detrimento de seus moradores originários. De fato, a gentrificação é uma consequência esperada e desejada do projeto, que conta com a valorização imobiliária para o atingimento dos objetivos remuneratórios definidos pela parceria público-privada (GAFFNEY, 2013:11).

Apesar das remoções, parte dos moradores de classe baixa resistiram e permanecem na região, a exemplo do Morro da Providência, favela situada dentro do perímetro do projeto. Apesar da permanência ser precária no sentido se sua insegurança jurídica, impacta os projetos

\footnotetext{
7 Empresa privada, que tem por acionistas três grandes empreiteiras: Odebrecht, OAS e Carioca Engenharia.

${ }^{8}$ Apenas no Morro da Providência, 140 famílias foram removidas de um total de 832 . Outras 692 chegaram a ser ameaçadas de remoção pelo poder público, tendo, no entanto, permanecido no território após diversas ações de resistência. Os dados são do dossiê do comitê popular da Copa e Olimpíadas do Rio de Janeiro.
} 
para a região por vezes desencadeando medidas importantes por parte do Estado como subsídios e obras de melhoramento.

Neste contexto, cabe destacar a aprovação do Plano de Habitação de Interesse Social do Porto Maravilha ${ }^{9}$, finalizado no ano de 2015 que, entretanto não se mostrou capaz de reverter a tendência de valorização e substituição populacional da área acima destacada. Isto porque embora traga em seu bojo previsões de instrumentos urbanísticos inovadores como a cota social nas construções, além do aluguel social, peca pela falta de estabelecimento de metas práticas e de garantia de manutenção da população originária na localidade (OBSERVATÓRIO DAS METRÓPOLES, 2015).

Como exemplo, o aluguel social previsto para famílias com renda de até 8 salários mínimos parece privilegiar a classe média e não os mais pobres, enquanto que a margem dada para alocação dos moradores originários atingidos pelas obras nas franjas do projeto, parece manter a lógica de valorização da região, com a retirada do "indesejáveis" e abertura de espaço para processos de gentrificação.

Na região portuária do Rio de Janeiro, diferentemente do que verificado no Pelourinho e no Bairro Recife, podemos dizer que eventual processo de gentrificação estaria relacionado, preponderantemente, não ao patrimônio histórico e cultural da região (embora essa dimensão também seja valorizada, a exemplo da restauração do Cais do Valongo, reconhecimento e estímulo ao Cemitério dos Pretos Novos e valorização artística do Morro da Conceição), mas sim às novas estruturas urbanas ligadas ao lazer e à cultura, que em tese beneficiariam todos os moradores da cidade.

Dos casos brasileiros analisados, o da zona portuária carioca parece ser o que mais se aproxima do conceito de gentrificação clássico, com observância de seus requisitos básicos já identificados anteriormente de intervenção territorial conjugada com a substituição de habitantes. No entanto, trata-se de processo recente e ainda não consolidado, o que prejudica qualquer afirmação mais incisiva sobre seu caráter gentrificador. Nos resta aguardar e acompanhar seu desenrolar para verificar com mais segurança o fenômeno.

\footnotetext{
${ }^{9}$ Disponível em: http://www.portomaravilha.com.br/habilitacao_social. Consultado em 15 de março de 2016.
} 


\section{CONCLUSÃO}

O presente trabalho pretendeu, a partir de uma breve análise do conceito de gentrificação, problematizar sua utilização na categorização de diversos processos em curso em cidades latino-americanas e brasileiras, de forma mais específica.

No capitalismo avançado, marcado pela hierarquização urbana e pela transformação das próprias cidades em mercadorias, as políticas de redesenvolvimento urbano ganham importância para as dinâmicas de produção e circulação do capital nas cidades, tendo como estratégia e/ou consequência processos de gentrificação.

Os processos de redesenvolvimento que têm por consequência a gentrificação de determinadas áreas nas cidades implicam uma seletividade dos investimentos que favorecem o capital em detrimento da "cidade da maioria", com particular gravidade para as áreas mais carentes onde se concentram os mais desfavorecidos (MENDES, 2010). A gentrificação, neste contexto, deve ser vista como uma das consequências mais drásticas da capitalização das cidades em detrimento dos mais pobres, com a negação de seus direitos mais básicos, como o de moradia, dada sua expulsão de territórios redesenvolvidos sem possibilidade de se beneficiar das intervenções físicas realizadas - via de regra agregadoras de infraestrutura e amenidades locacionais.

Importante destacar nestes apontamentos finais que, apesar do caráter perverso e da negação de direitos aos moradores mais desfavorecidos das áreas redesenvolvidas, a gentrificação vem sendo apresentada recentemente como efeito positivo e até desejado das intervenções urbanas. Associada a um discurso de limpeza, segurança e melhoria da região que sofre a intervenção e seu entorno, a gentrificação se apresenta no discurso como solução ótima, escondendo seu caráter excludente, segregador e de negação de direitos aos mais pobres (SMITH, 2002; CRESTANI, 2015).

Em um cenário de disputa discursiva e analítica sobre o tema, que cresce em importância e se dissemina em pesquisas teóricas e empíricas, buscamos resgatar as origens do conceito e seu desenvolvimento histórico a fim de compreender seus elementos básicos e firmar um marco conceitual para sua aplicação. Deste modo, apesar de toda a discussão teórica envolvendo os limites do conceito e sua possível ampliação, defendemos que sua utilização deve estar condicionada à observação de, ao menos, dois requisitos mínimos: a intervenção física no território e a substituição de moradores mais pobres por outros pertencentes a classes mais abastadas. 
De fato, um conceito que abarca uma infinidade de situações absolutamente distintas entre si sem a observância de requisitos mínimos não parece de muita utilidade na categorização e análise dos processos que pretende descrever. É exatamente com a preocupação de que a gentrificação se transforme em um desses conceitos que apresentamos o presente estudo.

Neste sentido, buscamos aplicar este marco conceitual em uma revisão bibliográfica sobre três casos concretos no Brasil, dentre os quais entendemos que os requisitos para a utilização do conceito de gentrificação apenas poderiam se apresentar em um deles, Rio de Janeiro, ainda que de forma preliminar pelo caráter recente dos processos de transformação territorial.

Nos demais casos, que são apenas representativos de uma variedade de outros para os quais vem sendo utilizado o conceito de gentrificação, não há dúvidas que se está diante de processos importantes de transformação socioespacial, que merecem estudo e categorização próprios, sem os "malabarismos" que muitas vezes são feitos para adequá-los (e a tantos outros) no conceito de gentrificação.

Nos parece fundamental a ênfase nas especificidades locais para a análise de qualquer processo de transformação socioespacial, especialmente nas cidades do sul global com um registro histórico tão peculiar. Neste sentido, antes de uniformizar os fenômenos sob uma mesma categoria que nem sequer foi formulada na realidade latino-americana como a gentrificação, seria importante um esforço de compreensão e desenvolvimento conceitual próprio, baseado em metodologia que permita aprofundar a visão dos processos específicos que abarcam as cidades latino-americanas, em geral, e brasileiras, em particular. Sendo assim, fica a necessidade de um aprofundamento das reflexões propostas no presente trabalho, e da utilização criteriosa, a fim de não sobrecarregar, um já tão complexo conceito como o da gentrificação e não "esconder" nele fenômenos distintos, que merecem uma formulação teórica própria.

\section{REFERÊNCIAS}

ANDREATTA, V. Porto Maravilha Rio de Janeiro: 6 casos de sucesso de revitalização portuária. Rio de Janeiro: Casa da Palavra, 2010.

BETANCUR, John J. Gentrification in Latin America: Overview and Critical Analysis. Urban Studies Research. Disponível em: <http://www.hindawi.com/journals/usr/2014/986961/>. Acesso em 15 de dezembro de 2015 
BIDOU-ZACHARIASEN, Catherine. De volta à cidade: dos processos de gentrificação às políticas de "revitalização" dos centros urbanos. Anablume: São Paulo, 2006.

BONFIM, J. D. Salvador da Bahia: estudo geográfico do Centro Histórico e a sua integração sóciourbana. Tese de doutorado. Salamanca, Universidade de Salamanca, 2007.

CADERNOS METRÓPOLE, v. 16, n.32. Desenvolvimento desigual e gentrificação na cidade contemporânea. Observatório das Metrópoles, 2014.

CARLOS, Claudio Antonio S.L. Uma olhar crítico à zona portuária do Rio de Janeiro. Bitacora Urbano-Territorial, n. 17 (2). Bogotá: Universidad Nacional de Colombia, 2010.

CARRERA, Óscar Muñoz. Gentrificación, segregación y reestructuración social enmadrid / gentrification, segregation and social restructuring in Madrid. Revista de Direito da Cidade, v.6, n.1, 2014.

CBN. Especulação faz moradores se mudarem de favelas da Zona Sul do Rio. Disponível em: <http://cbn.globoradio.globo.com/rio-de-janeiro/2014/04/17/ESPECULACAO-IMOBILIARIA-FAZMORADORES-SE-MUDAREM-DE-FAVELAS-DA-ZONA-SUL-DO-RIO.htm>. Acesso em 12 de abril de 2017.

CHECA-ARTASU, Martín Manuel. Gentrificación y cultura: algunas reflexiones. Revista Bibliográfica de Geografía y Ciencias Sociales, vol. XVI, no 914, 2011.

COMITÊ POPULAR DA COPA E OLIMPÍADAS DO RIO DE JANEIRO. Megaeventos e Violações dos Direitos Humanos no Rio de Janeiro: dossiê do Comitê Popular da Copa e Olimpíadas do Rio de Janeiro. Rio de Janeiro, 2015.

CRESTANI, Andrei M. Z. As faces (in)visíveis da regeneração urbana: rua Riachuelo e a produção de um cenário gentrificado, In: Cadernos Metrópole, v. 17, n. 33, 2015.

DAVIDSON, M.; LEES, L. New-build 'gentrification' and London's Riverside renaissance. Environment and planning, vol.37, 2005.

GAFFNEY, Christopher. Forjando os anéis: a paisagem imobiliária pré-olímpica no Rio de Janeiro. Revista Eletrônica de Estudos Urbanos - E-metropolis, São Paulo, n. 15, ano 4, págs. 15-29. Disponível em: <http://www.emetropolis.net/download/ edicoes/emetropolis_n15.pdf>. Acesso em: 24 de janeiro de 2016.

GILLESPIE, Patrick. How gentrification may benefit the poor. Disponível em:< http://money.cnn.com/2015/11/12/news/economy/gentrification-may-help-poor-people/>. Acesso em 15 de abril de 2017.

GLASS, Ruth. Aspects of Change. London: MacGibbon\&Kee, 1964.

HAMNETT, Chris. The blind men and the elephant: the explanation of gentrification. Transactions of the Institute of British Geographers. Vol.16, n.2, 1991. 
LEBRETON, A.; MOUREL, G. La gentrification comme articulation entre formeur baine et globalization: approche comparative Londres/Berlin. In : Espaces et societies, no 132-133, 2008. LEFEBVRE, Henri. O direito à cidade. São Paulo: Centauro, 2011.

LEITE, Rogério Proença. Contra Usos e Espaço Público: notas sobre a construção social dos lugares na Manguetown. Revista Brasileira de Ciências Sociais, vol.17, no 49, 2002.

A exaustão das cidades: antienobrecimento e intervenções urbanas em cidades brasileiras e portuguesas. In: Revista Brasileira de Ciências Sociais, vol.25, no 72, 2010.

LEY, David. Inner city revitalization in Canada: a Vancouver case study. Canadian Geography, n. 25. Vancouver, 1981.

MENDES, Luís. O contributo de Neil Smith para uma geografia crítica da gentrificação. Emetropolis, n.1, ano 1, 2010.

NOBRE, Eduardo A. C. Intervenções urbanas em Salvador: turismo e "gentrificação" no processo de renovação urbana do Pelourinho. Anais do X Encontro da Associação Nacional de Pósgraduação e pesquisa em planejamento urbano e regional. Belo Horizonte, 2003. Disponível em: http://www.unuhospedagem.com.br/revista/rbeur/index.php/anais/article/view/2348. Acesso em 07 de fevereiro de 2017.

RÉRAT, Patrick et al. New Forms of Gentrification: Issues and Debates. Population, Space and Place, n. 16, 2010. Disponível em: http:/www.interscience.wiley.com. Acesso em 24 de novembro de 2015.

RIBEIRO, Daniel A. Reflexões sobre o conceito e a ocorrência do processo de gentrification no Parque Histórico do Pelourinho, Salvador-BA. In: Cadernos Metrópole, São Paulo, v. 16, n. 32, 2014.

RODRIGUES, Sérgio. Gentrificação, o que é isso?. Disponível em: <http://veja.abril.com.br/blog/sobre-palavras/gentrificacao-o-que-e-isso/>. Acesso em 12 de abril de 2017.

SALINAS ARREORTUA, Luis Alberto. Gentrificación em la ciudad latinoamericana. El caso de Buenos Aires y Ciudad de México. GeoGraphos, vol.4, n. 44, 2013.

La gentrificación de la colonia condessa, ciudad de México, aporte para una discusión desde latinoamerica. Revista Geográfica, n. 51, 2013.

SAMPAIO, Julio Cesar Ribeiro. Gentrification: is it possible to avoid it?.City\& Time, 3 (2):3, 2007. Disponível em <http://www.ct.ceci-br.org>. Acesso em 01 de julho de 2015.

SANCHEZ, Fernanda. A reinvenção das cidades para um mercado global. Chapeco, Santa Catarina: ARGOS, 2010.

SANFELICI, Daniel de Mello. Urbanismo neoliberal e gentrificação: as políticas de revitalização do centro de Porto Alegre/RS. In: Ciênc.let., n. 41, 2007. 
SMITH, Neil. A gentrificação generalizada: de uma anomalia local à "regeneração" urbana como estratégia urbana global. De Volta à cidade: dos processos de gentrificação às políticas de "revitalização" dos centros urbanos. São Paulo: Annablume, 2006.

The new urban frontier - Gentrification and the revanchist city. London: Routledge, 1996. Gentrificação, a fronteira e a reestruturação do espaço urbano (trad. Daniel de Mello Sanfelici). GEOUSP - Espaço e tempo, n. 21, 2007.

New Globalism, new urbanism: gentrification as global urban strategy. Oxford: Blackwell Publishers, 2002.

Toward a theory of gentrification: a back to the city movement by capital, not people. Journal of the American Planning Association. London: Routledge, 1979.

THE ECONOMIST. Gentrification is good for the poor. Disponível em: <http://www.businessinsider.com/gentrification-is-good-for-the-poor-2015-2>. Acesso em 16 de abril de 2017.

ZUKIN, S. The cultures of cities. Cambridge: Blackwell, 1995.

Trabalho enviado em 16 de novembro de 2017

Aceito em 07 de março de 2018. 